\title{
COMPARAÇÃO DE MÉTODOS DE MONITORAMENTO E CONTROLE DO BICHO-FURÃO, Ecdytolopha aurantiana (LIMA, 1927) (LEPIDOPTERA, TORTRICIDAE), EM CITROS
}

\section{DIOGO RODRIGUES CARVALHO}

\footnotetext{
Dissertação apresentada à Escola Superior de Agricultura "Luiz de Queiroz", Universidade de São Paulo, para obtenção do título de Mestre em Ciências, Área de Concentração: Entomologia.
}

\author{
PIRACICABA \\ Estado de São Paulo - Brasil \\ Agosto - 2003
}




\title{
COMPARAÇÃO DE MÉTODOS DE MONITORAMENTO E CONTROLE DO BICHO-FURÃO, Ecdytolopha aurantiana (LIMA, 1927) (LEPIDOPTERA, TORTRICIDAE), EM CITROS
}

\section{DIOGO RODRIGUES CARVALHO}

Engenheiro Agrônomo

Orientador: Prof. Dr. JOSÉ ROBERTO POSTALI PARRA

\begin{abstract}
Dissertação apresentada à Escola Superior de Agricultura "Luiz de Queiroz", Universidade de São Paulo, para obtenção do título de Mestre em Ciências, Área de Concentração: Entomologia.
\end{abstract}

PIRACICABA

Estado de São Paulo - Brasil

Agosto - 2003 
Dados Internacionais de Catalogação na Publicação (CIP)

DIVISÃO DE BIBLIOTECA E DOCUMENTAÇÃO - ESALQ/USP

\section{Carvalho, Diogo Rodrigues}

Comparação de métodos de monitoramento e controle do bic hofurão, Ec dytolopha a ura ntia na (Lima , 1927) (Lepidoptera, Tortricidae), em citros/ Diogo Rodrigues Carvalho. - - Piracicaba, 2003.

38 p. : il.

Dissertação (mestrado) - - Escola Superior de Agricultura Luiz de Queiroz, 2003.

Bibliografia.

1. Armadilha para inseto 2. Bicho-furão - Fase adulta 3. Controle químic 4. Dieta artific ial 5. Exigência témica 6. Feromônios sexua is 7. Frutas cítric as I. Título

CDD 634.3

"Permitida a cópia total ou parcial deste documento, desde que citada a fonte - O autor" 
Aos meus pais,

Com todo o meu amor

Agradeço

À minha irmã Gabriela,

Meus sobrinhos Gabriel e Marina

Dedico

À minha avó Mercedes,

Fonte de força e luz

Ofereço 


\section{AGRADECIMENTOS}

Ao Dr. José Roberto Postali Parra, professor Titular do Departamento de Entomologia, Fitopatologia e Zoologia Agrícola, da ESALQ/USP, pela orientação, atenção e apoio nesses anos e a quem admiro como profissional e ser humano brilhante;

Ao Fundecitrus, pela concessão da bolsa de estudos que viabilizou minha participação no curso de Pós-Graduação;

Aos professores do Departamento de Entomologia, Fitopatologia e Zoologia Agrícola da ESALQ/USP, pelos conhecimentos transmitidos;

À Neide Graciano Zério, técnica do Laboratório de Biologia de Insetos pela valiosa amizade e grande colaboração para a realização dos trabalho;

Ao Engenheiro Agrônomo Msc. Peter Kasten Júnior pela amizade construída e grande ajuda nesses anos de estudo;

À Faculdade de Ciências Agrárias e Veterinárias de Jaboticabal (UNESP), pela valiosa contribuição na minha formação pessoal;

À Gravena Manecol, na pessoa do Prof. Dr. Santin Gravena, pelo apoio e incentivo para seguirmos na área de controle biológico; 
Aos colegas de laboratório Dori, Amauri, Sandra, Adriana, Jerson, Priscila, Patrícia, Ana Lia, Cristina, Picasso, José Francisco, pelo agradável convívio, amizade e auxilio durante todo o período que estive no Laboratório de Biologia de Insetos;

Aos funcionários do Departamento de Entomologia, Fitopatologia e Zoologia Agrícola da ESALQ/USP, em especial ao Carlinhos, Tutu, Dino, Vitor, João Gorá, João Fortes e Aninha;

Aos colegas do curso de Pós-graduação em Entomologia, Ricardo, Moisés, Fito, Marcel, Fabiana, Luciana, Fabiane, Milena, Rosa, Poleti, Jorge, Sallas, Rita, Cássia, Daniela, Marcão, pelos momentos alegres que passamos esses anos;

Ao Prof. Dr. José Maurício Simões Bento, pela amizade e dicas valiosas para desenvolvimento desse trabalho;

Ao Biólogo Heraldo Negri de Oliveira pelo auxílio na parte fotográfica e amizade;

Ao amigo Engenheiro Agrônomo Danilo Scacalossi Pedrazzoli, pelo apoio, companheirismo, grande amizade e incentivo para conclusão desse trabalho;

Ao Prof. Dr. Alexandre de Sene Pinto pela contribuição na formatação, análises e ajuda na correção desse trabalho. 


\section{SUMÁRIO}

Página

LISTA DE FIGURAS .................................................................................. viii

LISTA DE TABELAS ...............................................................................

RESUMO ….......................................................................................... xii

SUMMARY ................................................................................................ xiv

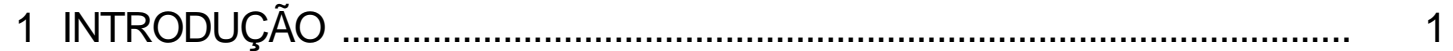

2 REVISÃO DE LITERATURA .................................................................. 3

2.1 Aspectos gerais ................................................................................ 3

2.2 Biologia e comportamento ................................................................ 4

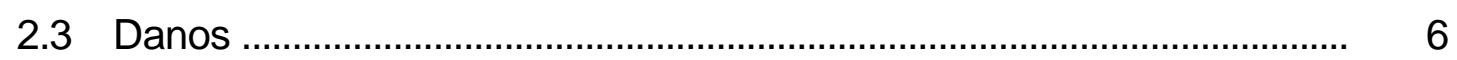

2.4 Importância econômica .......................................................................... 7

2.5 Manejo e controle ..................................................................................... 7

3 MATERIAL E MÉTODOS ........................................................................ 10

3.1 Comparação da eficiência de três métodos para monitoramento de adultos de Ecdytolopha aurantiana (Lima, 1927) (Lepidoptera: Tortricidae) ......................................................................................... 10

3.1.1 Método da armadilha com feromônio sexual ..................................... 12

3.1.2 Método da dieta artificial .................................................................... 14

3.1.3 Método da previsão através das exigências térmicas do inseto ........ 16

3.1.3.1 Determinação do fator de correção das exigências térmicas para as diferentes estações do ano

3.2 Determinação do nível de controle de $E$. aurantiana utilizando-se armadilha com feromônio sexual (Ferocitrus Furão ${ }^{\circledR}$ ) 
Página

3.3 Determinação do tempo de penetração de lagartas recém eclodidas de E. aurantiana

3.4 Avaliação do efeito de agroquímicos sobre adultos de E. aurantiana ... 21

4 RESULTADOS E DISCUSSÃO

4.1 Comparação da eficiência dos três métodos para monitoramento de adultos de Ecdytolopha aurantiana (Lima, 1927) (Lepidoptera: Tortricidae)

4.1.1 Determinação do fator de correção para as diferentes estações do ano para o método de exigências térmicas

4.1.2 Comparação das datas indicadas e número de frutos atacados para cada método de amostragem

4.2 Determinação do nível de controle de E. aurantiana utilizando-se armadilha com feromônio sexual

4.3 Determinação do tempo e profundidade de penetração de lagartas recém eclodidas de $E$. aurantiana em frutos

4.4 Avaliação do efeito de agroquímicos sobre adultos de $E$. aurantiana ... 30

5 CONCLUSÕES 32

5.1 Considerações finais 33 REFERÊNCIAS BIBLIOGRÁFICAS 


\section{LISTA DE FIGURAS}

Página

1 Mapa do local de instalação do experimento de comparação da eficiência de métodos de amostragem de Ecdytolopha aurantiana. Gavião Peixoto, SP, 2002

2 Vista aérea do talhão onde foi instalado o experimento de comparação da eficiência de métodos de amostragem de Ecdytolopha aurantiana. A. Método da armadilha de feromônio; B. Método da dieta artificial; C. Métodos das exigências térmicas. Gavião Peixoto, SP, 2002

3 Local de instalação da armadilha de feromônio sexual (Ferocitrus Furão ${ }^{\circledR}$ ) colocada na parte superior da planta com auxílio de um mastro de bambu

4 Ficha ilustrada para identificação dos ínstares das lagartas de Ecdytolopha aurantiana

5 Abrigo de madeira para os tubos contendo dieta artificial e lagartas de Ecdytolopha aurantiana mantido em condições de campo

6 "Kit" do feromônio sexual Ferocitrus Furão ${ }^{\circledR}$ comercializa do no Brasil 
7 Vista geral do experimento para determinação do tempo de penetração das lagartas recém eclodidas de Ecdytolopha aurantiana em frutos de laranja variedade Pêra

8 Gaiolas de ferro contendo frutos de citros e onde foram colocados adultos de Ecdytolopha aurantiana, utilizadas no ensaio de campo para verificar a eficiência de agroquímicos no controle dessa praga 


\section{LISTA DE TABELAS}

Página

1 Composição da dieta artificial para a criação de lagartas de Ecdytolopha aurantiana

2 Temperatura base (Tb) para os diferentes ínstares larvais de Ecdytolopha aurantiana (J.R.P. Parra, inf. pessoal)

3 Tratamentos utilizados, e suas respectivas dosagens, visando ao controle de adultos de Ecdytolopha aurantiana

4 Constante térmica (GD) teórica (de laboratório) e real (de campo) e respectivos fatores de correção para a fase larval-pupal de Ecdytolopha aurantiana obtidos para as diferentes estações do ano. Piracicaba, SP, 1999

5 Definição das datas de aplicação de agroquímicos para controle de Ecdytolopha aurantiana, com base em três métodos de amostragem. Gavião Peixoto, SP, 2001

6 Número médio de frutos atacados/planta nos diferentes métodos de amostragem para Ecdytolopha aurantiana. Gavião Peixoto, SP, 2001 ..... 
7 Número médio de frutos de laranja Pêra atacados por Ecdytolopha aurantiana por planta, em cada nível de controle testado (com armadilha de feromônio sexual), e o número médio de aplicações de inseticidas em cada tratamento. Gavião Peixoto, SP, 2001

8 Tempo de penetração de lagartas recém eclodidas de Ecdytolopha aurantiana em frutos de laranja variedade. 'Pêra'

9 Profundidade de penetração e mortalidade de lagartas recém eclodidas de Ecdytolopha aurantiana em diferentes intervalos após a inoculação em frutos de laranja variedade. 'Pêra'

10 Mortalidade (\%) de adultos de Ecdytolopha aurantiana em campo, nos diferentes tratamentos utilizados. Gavião Peixoto, SP, 2001 


\title{
COMPARAÇÃO DE MÉTODOS DE MONITORAMENTO E CONTROLE DO BICHO-FURÃO, Ecdytolopha aurantiana (LIMA, 1927) (LEPIDOPTERA, TORTRICIDAE), EM CITROS
}

\author{
Autor: DIOGO RODRIGUES CARVALHO \\ Orientador: Prof. Dr. JOSÉ ROBERTO POSTALI PARRA
}

\section{RESUMO}

O presente trabalho teve como objetivo comparar três métodos de amostragem de adultos do bicho-furão, quais sejam: 1) monitoramento com armadilhas de feromônio sexual; 2) monitoramento do inseto criado no campo em dietas artificiais; 3) previsão baseada em exigências térmicas do inseto. Para complementar tal pesquisa, que visa facilitar o manejo e o controle da praga, foram estudados o nível de controle para o método utilizando-se feromônio sexual e o efeito de agroquímicos sobre a fase adulta do inseto com base no monitoramento mais adequado. Os três métodos de monitoramento de Ecdytolopha aurantiana (Lima, 1927) mostraram eficiência para serem utilizados em condições de campo. O método de monitoramento do bicho-furão por meio de feromônio sexual foi o que exigiu menor mão-de-obra. O método de monitoramento através de exigências térmicas foi aplicável no verão, exigindo fatores de correção para as demais estações do ano. O nível de controle, determinado para o monitoramento com feromônio sexual, foi de 4 a 6 adultos/semana; a partir destes números, as perdas foram maiores a despeito 
do maior número de aplicações de produtos químicos. Como o tempo de penetração da lagarta do bicho-furão foi rápido (100\% em 24 h), com cerca de 42,9\% atingindo a polpa em 72 h, torna-se difícil o controle do inseto nesta fase através de produtos químicos ou biológicos. A alta mortalidade larval do bichofurão durante a penetração no fruto, pode mascarar os resultados de avaliação da eficiência de controle com produtos químicos ou biológicos. O piretróide bifentrine foi eficiente no controle de adultos de $E$. aurantiana, desde que adicionado a óleo mineral. 


\title{
COMPARISON OF Ecdytolopha aurantiana (LIMA, 1927) (LEPIDOPTERA, TORTRICIDAE) MONITORING METHODS AND CONTROL IN CITRUS
}

\author{
Author: DIOGO RODRIGUES CARVALHO \\ Adviser: Prof. Dr. JOSÉ ROBERTO POSTALI PARRA
}

\section{SUMMARY}

The goal of this work was to compare three sampling methods for adult citrus fruit borer, as follows: 1) monitoring with sexual pheromone traps; 2) monitoring of insects reared under artificial diets in the field; 3) Forecasting based on the thermal requirements of the insect. In order to complete this research, which is intended for an easier pest management and control, one studied the control level for the method with sexual pheromone and the effects of agrochemicals on the adult stage of the insect based on the more suitable monitoring. All three methods of Ecdytolopha aurantiana (Lima, 1927) monitoring were efficient under field conditions. The citrus fruit borer monitoring method by means of sexual pheromone was the least laborious one. The monitoring method through thermal requirements was applicable in the summer, requiring correction factors in the remaining seasons of the year. The control level as determined for the sexual pheromone monitoring was 4 to 6 adults/week; following these figures, the losses were greater despite the higher amount of chemicals application. Since the penetration time of the citrus fruit 
borer was brief (100\% in $24 \mathrm{~h})$, with approximately $42.9 \%$ reaching the pulp in $72 \mathrm{~h}$, it is difficult to control the insect at this stage through chemical or biological products. The high larval mortality of the citrus fruit borer during fruit penetration can conceal the results of the control efficiency evaluation with chemical or biological products. Pyrethroid bifenthrin was efficient to control adult $E$. aurantiana provided that mineral oil was added. 


\section{INTRODUÇÃO}

Nos últimos anos, o Brasil apresentou um considerável aumento da produção citrícola. De 415 milhões de caixas, em 1998, passou para 454 milhões em 2000, sendo a região Sudeste responsável por $85,5 \%$ da produção brasileira (FNP, 2001).

Dentre os fatores limitantes à produção de citros no país estão as pragas, pelos danos que causam, exigindo elevados gastos com mão-de-obra, além de aplicações de alto volume de agroquímicos. Dentre as pragas de importância econômica que ocorrem na cultura, atualmente, destaca-se o bichofurão-dos-citros, Ecdytolopha aurantiana (Lima, 1927). O ataque dessa praga, em São Paulo, inicia-se a partir de novembro, aumentando nos meses de janeiro, fevereiro e março. Altas infestações podem causar até $50 \%$ de perdas de frutos, sendo Pêra, Natal e Valência as variedades mais atacadas por essa praga, embora ela possa ocorrer também em outras variedades (Prates, 1992).

Uma das limitações para controlar este inseto é a dificuldade em se determinar a época correta de aplicação dos agroquímicos. O monitoramento através de amostragens poderá definir o momento correto da aplicação. Segundo Garcia (1998), dada à característica da postura, as amostragens de ovos do bicho-furão para levantamentos populacionais são inviáveis e essa amostragem, segundo o autor, deve ser feita baseando-se na população de adultos, pois quando se inicia o controle onde já existem frutos atacados, é muito difícil conseguir-se bons níveis de controle, pois a partir do início do 
ataque a praga tem a característica de "explodir", em curto espaço de tempo, seus níveis populacionais (Parra J. R. P., inf. pessoal).

Desta forma, o presente trabalho teve como objetivo comparar três métodos de amostragem de adultos do bicho-furão, incluindo-se: 1) monitoramento com armadilhas de feromônio sexual; 2) monitoramento do inseto criado no campo em dietas artificiais; 3) previsão baseada em exigências térmicas do inseto. Para complementar tal pesquisa, que visa facilitar o manejo e o controle da praga, foram estudados o nível de controle para o método utilizando-se feromônio sexual e o efeito de agroquímicos sobre a fase adulta do inseto com base no monitoramento mais adequado. 


\section{REVISÃO DE LITERATURA}

\subsection{Aspectos gerais}

Este inseto foi relatado pela primeira vez por Bondar, em 1915, em laranjas, sendo identificado como Tortrix citrianaFernald (Lima, 1927; 1945).

Em 1927, Costa Lima descreveu o inseto como Gymnandrosoma aurantianum, incluindo-o na família Olethreutidae. Em 1945, o mesmo autor classificou-o na família Grapholitidae e, recentemente, Powell et al. (1995) transferiram G. aurantianum para Ecdytolopha aurantiana (Lima, 1927), pertencente àfamília Tortricidae (Powell et al., 1995).

O nome comum mais usado para esta praga no Brasil é bicho-furão-doscitros (Prates et al., 1981; Prates \& Pinto, 1988; Nakano \& Leite, 1998); esta espécie ocorre em toda a América do Sul (Zucchi et al., 1993). Assim, White (1993) observou E. aurantiana causando severos danos æ̀े plantas de citros em 1992 e 1993 em Trinidad-Tobago e Dominica.

Em trabalho realizado por Nakano \& Leite (1998), os autores indicaram que a região de Catanduva favorece a ocorrência da praga pelo seu clima e mostraram também que $E$. aurantiana não apresentou preferência pelas variedades existentes, sendo todas atacadas. As variedades tardias sofreram maior incidência da praga, tendo em vista que as gerações vão se sucedendo e conseqüentemente aumentando. 
Esta praga ocorre em São Paulo a partir de novembro, com picos entre fevereiro e março, mas pode ocorrer o ano todo, causando perdas de até duas caixas de laranja por planta (Nakano \& Soares, 1995). Em função dessas perdas, passou a ser considerada uma das principais pragas da cultura a partir da década de 90 (Prates \& Pinto, 1991; Garcia et al., 1998; Garcia \& Parra, 1999).

\subsection{Biologia e comportamento}

As mariposas de E. aurantiana colocam os ovos na superfície dos frutos e o período de incubação é de três a cinco dias (Pinto, 1994; 1995; Nakano \& Soares, 1995). Estes últimos autores observaram ainda que os ovos podem ser colocados nas folhas, de forma isolada, sendo achatados e transparentes, e a lagarta, logo que eclode, penetra no fruto.

E. aurantiana tem hábito de postura crepuscular bem definido, seja em laboratório ou em campo. Os ovos de E. aurantiana, provenientes de criação em dieta artificial, apresentaram um período embrionário de aproximadamente cinco dias $(5,02 \pm 0,03)$, com um intervalo de variação de quatro a sete dias e viabilidade de $91,1 \%$ (Garcia, 1998). Após a eclosão, as lagartas penetram no interior do fruto, onde se alimentam da polpa. A maioria das lagartas chega, no máximo desenvolvimento, a atingir de 15 a 18mm de comprimento (Fonseca, 1934; Schultz, 1939), com um período larval de até 20 dias (Lima, 1927). Ao final deste período, abandonam o fruto para pupar no solo, protegendo a pupa tecendo um casulo composto de teia, fragmentos do solo e restos vegetais. Poucas lagartas pupam no próprio fruto. Após 12 a 20 dias, as pupas livram-se do casulo momentos antes da emergência e saem do solo como adultos (Lima, 1927; Schultz, 1939; White, 1993). Os adultos, de coloração acinzentada, têm 
as asas posteriores mais claras que as anteriores e apresentam cerca de 17 $\mathrm{mm}$ de envergadura (Fonseca, 1934).

Em frutos, E. aurantiana desenvolve-se melhor na variedade Natal, e em dieta artificial há uma redução no número de ínstares, indicando assim uma adequação nutricional da dieta ao inseto, pois além de diminuir o período de desenvolvimento, aumenta a viabilidade do período ovo-adulto, a taxa líquida de reprodução (Ro) e a razão finita de aumento ( $)$ (Garcia, 1998). Portanto, E. aurantiana apresenta as mesmas características do inseto de campo quando criado em dieta artificial (Garcia \& Parra, 1999). Garcia (1998) verificou que o inseto é muito sensível aos baixos valores de umidade relativa do ar (UR), diminuindo a longevidade e capacidade de postura nas baixas UR (30 e 50\%).

Solos muito encharcados ou secos afetam as pupas e diminuem a emergência de E. aurantiana (Parra, J.R.P., observação pessoal).

De acordo com Bento et al. (2001a), mais de $80 \%$ dos acasalamentos de E. aurantiana ocorrem no terceiro e quarto dias de vida do inseto adulto, sendo que as cópulas duram, em média, uma hora e 40 minutos, variando entre três minutos e cinco horas e 12 minutos. O acasalamento é mediado por um feromônio sexual emitido pelas fêmeas, que atrai os machos a longas distâncias.

A proporção sexual do bicho-furão é de aproximadamente 1:1 (macho: fêmea), e uma fêmea tem capacidade de colocar até 200 ovos, sendo que normalmente é colocado apenas um ovo por fruto (Garcia \& Parra, 1999). Ocorre o fenômeno de protandria na espécie (Bento et al., 2002). 


\subsection{Danos}

$O$ ataque de $E$. aurantiana caracteriza-se por um sintoma nos frutos que pode ser confundido com o das moscas-das-frutas (Prates \& Pinto, 1991). Entretanto, tal dano causado pelo bicho-furão é de fácil separação daquele causado pela moscas-das-frutas, pois no orifício de penetração a lagarta elimina as fezes, que ficam presas, secas e duras nesse local. As moscas-dasfrutas, além de uma região arredondada (podridão), deixam um orifício central nos frutos por onde sai a larva para pupar no solo e pelo qual sai um líquido, se o fruto for pressionado com as mãos (Gallo et al., 2002).

A penetração inicial no fruto, pelo primeiro ínstar larval, leva a infecções secundárias por fungos, bactérias, besouros e moscas-das-frutas. Uma área necrótica se desenvolve gradualmente ao redor do orifício de entrada, normalmente deprimida em relação ao resto da casca. $O$ fruto torna-se amarelo claro, amadurece prematuramente e cai. Frutos que não chegam a cair, ou que estejam maduros no momento da penetração, desenvolvem um brilho de coloração alaranjada bem distinta dos frutos sadios (Lima, 1927; Schultz, 1939; White, 1993). Frutos mais verdes, portanto mais ácidos, são também atacados pelo bicho-furão, especialmente em altas populações da praga, embora, nestes casos ocorra um alongamento do período larval e maior mortalidade do inseto (Parra et al., 2001).

A grande porcentagem de frutos atacados por E. aurantiana encontra-se entre um e dois metros de altura e, a maioria, do lado externo da planta (Garcia, 1998). O bicho-furão causa grandes prejuízos, pois o dano ocorre diretamente no fruto, tornando-o imprestável para indústria e consumo 'in natura' (Nakano \& Leite, 1998). 


\subsection{Importância econômica}

As perdas econômicas devido ao ataque de E. aurantiana são estimadas em cerca de 50 milhões de dólares/ano para a citricultura brasileira, pois os frutos ficam, após o ataque, imprestáveis para o comércio e indústria (Fundecitrus, 2000). Em Trinidad-Tobago, até 40\% dos frutos por planta cítrica foram danificados (White, 1993), sendo que no Brasil os surtos podem comprometer até 1,5 caixas de frutos por planta (Prates \& Pinto, 1988; 1995).

Garcia (1998) observou que a praga pode apresentar de sete a 8,2 gerações anuais nas principais regiões citrícolas do Estado de São Paulo, responsáveis por 85,5\% da produção brasileira (FNP, 2001).

\subsection{Manejo e controle}

Atualmente, o controle de E. aurantiana é feito basicamente através de produtos químicos, fisiológicos e biológicos, esses últimos formulados com Bacillus thuringiensis (Bt). Os produtos mais utilizados são mencionados em Prates et al. (1981), Prates \& Pinto (1988, 1992), Prates \& Pinto (1991), Pinto (1995), Guerreiro et al. (1997), Massanbani et al. (1997), Pazini \& Busoli (1997) e Pinto et al. (1997), Fundecitrus (2003).

Além do controle químico, a catação dos frutos caídos e também dos frutos atacados ainda nas plantas cítricas deve ser realizada (Prates \& Pinto, 1988), pois representa $70 \%$ da eficiência do controle (Pinto, 1994; 1996), sendo a medida complementar mais eficiente para interromper o ciclo do inseto (Citricultura, 1996). 
Até recentemente não existia uma metodologia de amostragem apropriada para indicar o melhor momento para se controlar a praga. A metodologia mais empregada era a avaliação de sintomas visuais nos frutos e aplicação de produtos a partir de uma determinada porcentagem de frutos atacados. Todavia, este método possui algumas imperfeições que são: (a) a fase do inseto amostrada (lagarta), não corresponde àquela que se pretende controlar, ou seja, o adulto ou a lagarta de primeiro ínstar e (b) ao se utilizarem os frutos danificados como parâmetro de amostragem, as lagartas que se encontram dentro desses, permanecem protegidas da ação dos produtos aplicados, assegurando uma nova geração da praga e a perda dos frutos já atacados (Bento et al., 2001b).

Garcia (1998) concluiu que a melhor forma de se amostrar a praga no campo é através dos adultos, pois toda a fase larval ocorre dentro do fruto e os ovos são de difícil visualização no campo, além da característica do bicho-furão atingir rapidamente os picos populacionais após seu aparecimento ("explosões" populacionais).

Bento et al. (2001a) demonstraram que o horário crepuscular é de grande importância no ritmo diário desta praga, especialmente o entardecer e as duas horas subseqüentes. A diminuição da luminosidade, associada a uma queda de temperatura e aumento da umidade relativa, características desse horário, desencadeiam uma série de eventos fisiológicos, que levam ao acasalamento e postura. De um modo geral, enquanto os machos e as fêmeas virgens se deslocam para o terço superior da planta de citros para acasalarem, as fêmeas já acasaladas fazem a postura no terço médio da planta. Este sincronismo faz com que não haja competição de machos por fêmeas acasaladas, o que poderia nterferir na atividade de postura dessas fêmeas neste horário. Do ponto de vista de manejo, este horário poderia ser indicado como o mais adequado para a aplicação de produtos químicos, pois os insetos estariam mais expostos àação desses agroquímicos. Aliás, esta é uma prática 
que já vem sendo adotada pelos citricultores do Estado de São Paulo visando ao controle de $E$. aurantiana.

Em 2001, o feromônio sexual da espécie foi sintetizado (Leal et al., 2001) e atualmente é comercializado pela Copercitrus com o nome de FerocitrosFurão ${ }^{\circledR}$, para monitoramento da praga.

Perspectivas de controle biológico existem, ou seja, através do parasitóide de ovos Trichogramma spp. (Garcia, 1998), sendo conduzidos estudos recentemente que apontam para a viabilidade de sua utilização (Molina, 2003). Também o parasitóide larval Hymenochaonia delicata (Cresson) ( Hymenoptera, Braconidae ), pode ser importante em determinadas épocas do ano, quando chega a parasitar mais de $50 \%$ das lagartas de E. aurantiana (Garcia, 1998). Devem ser intensificadas as pesquisas com estes agentes biológicos (Parra, 2002) 


\section{MATERIAL E MÉTODOS}

\subsection{Comparação da eficiência de três métodos para monitoramento de adultos de Ecdytolopha aurantiana (Lima, 1927) (Lepidoptera: Tortricidae)}

O trabalho foi realizado na fazenda Entre Rios, pertencente à empresa citrícola Fischer, localizada no município de Gavião Peixoto, SP (latitude: 21을 ; longitude: $48^{\circ} \mathrm{W}$; altitude: $496 \mathrm{~m}$ ) (Figura 1). O experimento ocupou uma área de 20 ha, com aproximadamente 5.000 plantas de laranja da variedade Natal, com idades entre oito e dez anos, correspondente a um talhão da fazenda (Figura 2). Esse talhão foi dividido em três sub-talhões iguais, sendo que cada um representou um bloco. Esses blocos constituíram-se de sete parcelas, representadas por 16 plantas cada, onde apenas as quatro plantas centrais foram submetidas à avaliações.

Cada método de amostragem para adultos de E. aurantiana foi considerado um tratamento, sendo eles: (1) método da armadilha com feromônio sexual; (2) método da dieta artificial; e (3) método das exigências térmicas. Cada método será descrito posteriormente (itens 3.1.1, 3.1.2 e 3.1.3) 


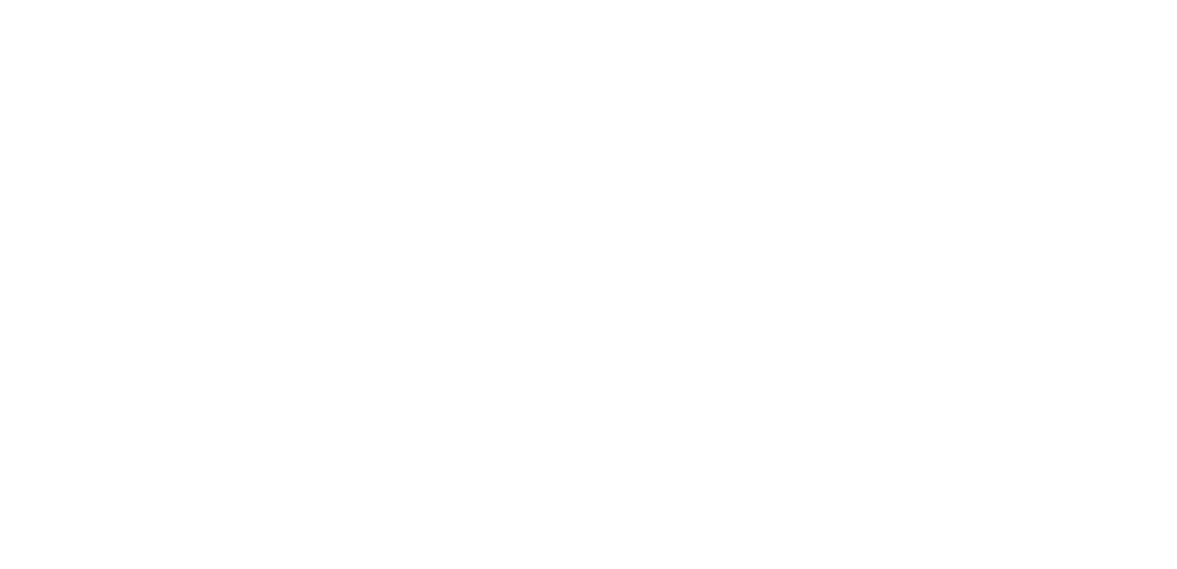

Figura 1 - Mapa do local de instalação do experimento de comparação da eficiência de métodos de amostragem de Ecdytolopha aurantiana. Gavião Peixoto, SP, 2002

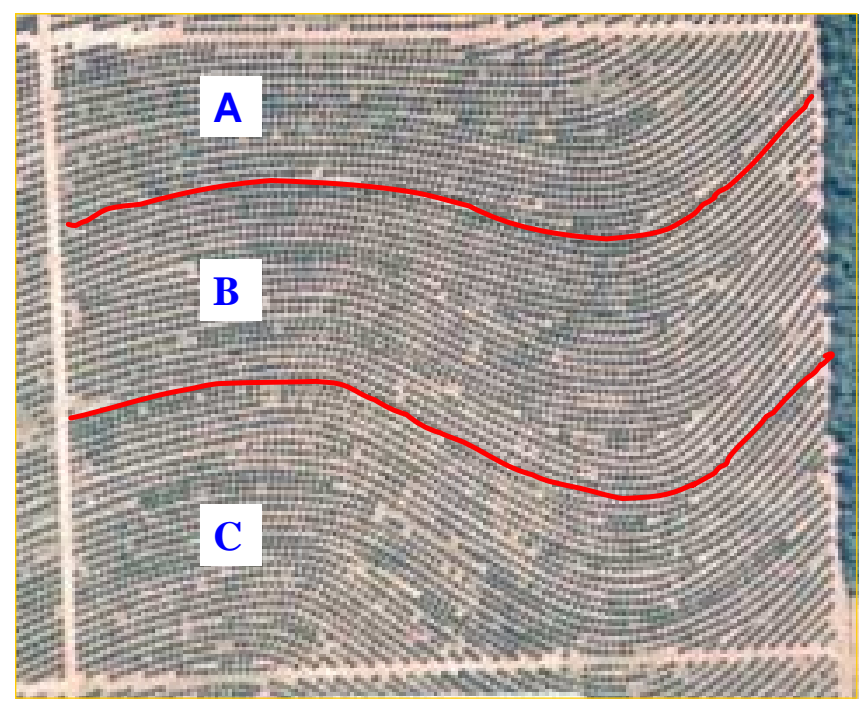

Figura 2 - Vista aérea do talhão onde foi instalado o experimento de comparação da eficiência de métodos de amostragem de Ecdytolopha aurantiana. A. Método da armadilha de feromônio; B. Método da dieta artificial; C. Métodos das exigências térmicas. Gavião Peixoto, SP, 2002 
Foram aplicados inseticidas imediatamente após ter sido atingido o nível de controle específico para cada método de amostragem. Assim, com base no número de aplicações para cada método e na contagem de frutos atacados após as aplicações do inseticida, foi avaliada a eficiência de controle para cada método.

Semanalmente, todos os frutos das quatro plantas centrais de cada parcela eram observados, o número de frutos com sintomas era anotado em ficha própria e aqueles danificados eram retirados da planta para não haver sobreposição de dados, ou seja, para evitar a contagem do mesmo em avaliações subseqüentes.

Foi realizado o controle químico nas parcelas experimentais, utilizandose o piretróide deltametrina (Decis), na dosagem de $300 \mathrm{ml}$ de produto comercial +70 litros de óleo/ha, aplicado com termonebulizador tratorizado. 0 horário de aplicação foi sempre ao entardecer, das 18:00h æ̀̀ 20:00h (horário de maior atividade do inseto - item 2.5). O período de avaliação foi de fevereiro de 2001 a fevereiro de 2002.

\subsubsection{Método da armadilha com feromônio sexual}

O bloco foi monitorado através de uma armadilha delta contendo o feromônio sexual de E. aurantiana (Ferocitrus Furão ${ }^{\circledR}$ ). Esse monitoramento foi feito utilizando-se uma armadilha delta, contendo cola "stick" e uma pastilha do feromônio sexual, que foi acoplada a um mastro de bambu para a colocação da mesma no terço superior da planta (Figura 3), local onde ocorre o acasalamento do bicho-furão (Bento et al., 2001a,b). A armadilha foi instalada na parte central do bloco A (Figura 2). 
Semanalmente, foram contados os adultos capturados na armadilha, retirando-os com o auxílio de uma espátula de madeira. O nível de controle considerado para esse método de amostragem foi de 4 adultos capturados por semana.

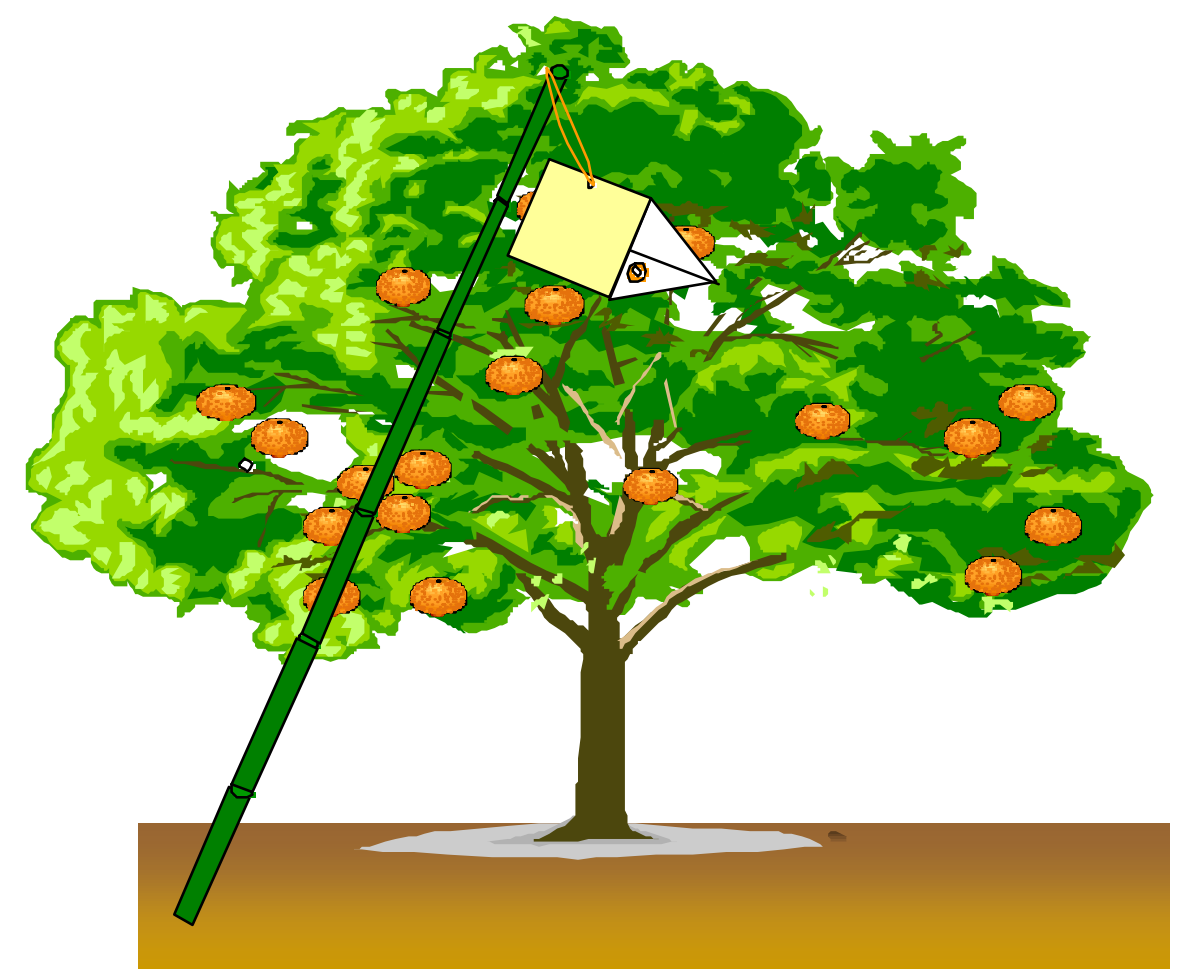

Figura 3 - Local de instalação da armadilha de feromônio sexual (Ferocitrus Furão ${ }^{\circledR}$ ) colocada na parte superior da planta com auxílio de um mastro de bambu 


\subsubsection{Método da dieta artificial}

Este método baseourse na criação do inseto em dieta artificial, mantido em condições de campo (Gallo et al., 2002). Semanalmente, foram coletados frutos no talhão com sintomas de ataque de $E$. aurantiana. $O$ número de frutos coletados variou conforme a época e infestação da praga. Esses frutos eram levados a um local protegido, onde se retiravam as lagartas para identificação do ínstar em que se encontravam. Essa identificação era feita através de uma ficha ilustrada com os diferentes ínstares da lagarta, baseada no tamanho da mesma (Figura 4).

A seguir, determinava-se o ínstar predominante na área. Depois de definido o ínstar, as lagartas eram colocadas em tubos de vidro, contendo dieta artificial (Tabela 1). Eram colocadas cerca de quatro lagartas por tubo, onde completavam seu desenvolvimento. $O$ número de tubos variou conforme o número de lagartas coletadas, sendo o mínimo de 30 e o máximo de 50 lagartas por semana. Esses tubos, contendo dieta artificial, eram colocados em um abrigo de madeira (Figura 5), que foi instalado no centro do bloco B, para imitar as condições de campo. A partir daí, acompanhava-se diariamente o desenvolvimento desses insetos. O nível de controle para esse método foi quando ocorria $60 \%$ de emergência dos adultos nos tubos contendo a dieta com os insetos em desenvolvimento. 


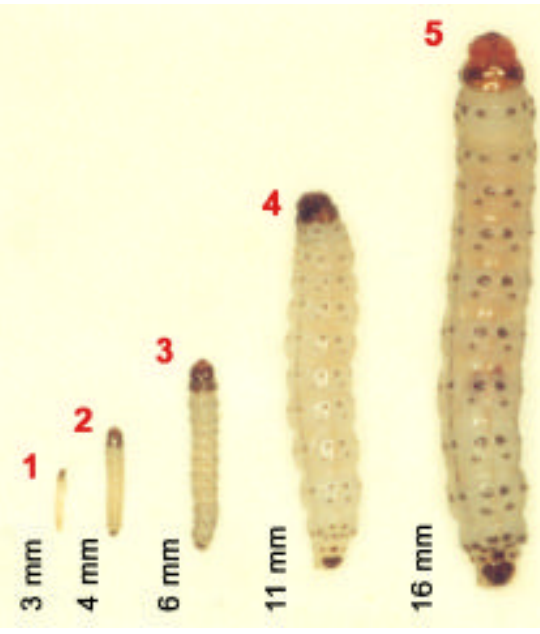

Figura 4 - Ficha ilustrada para identificação dos ínstares das lagartas de Ecdytolopha aurantiana

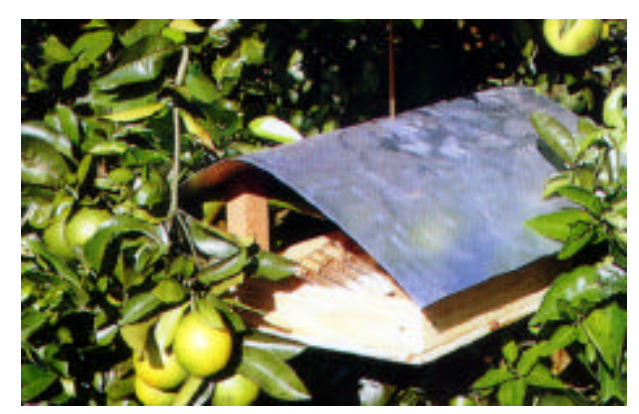

Figura 5 - Abrigo de madeira para os tubos contendo dieta artificial e lagartas de Ecdytolopha aurantiana mantido em condições de campo 
Tabela 1. Composição da dieta artificial para a criação de lagartas de Ecdytolopha aurantiana

\begin{tabular}{lc}
\hline Componentes & Quantidade \\
\hline Germe de trigo & $30,00 \mathrm{~g}$ \\
Levedura de cerveja & $18,75 \mathrm{~g}$ \\
Feijão & $37,50 \mathrm{~g}$ \\
Proteína de soja & $15,00 \mathrm{~g}$ \\
Caseína & $15,00 \mathrm{~g}$ \\
Solução vitamínica & $4,5 \mathrm{ml}$ \\
Ácido ascórbico & $1,80 \mathrm{~g}$ \\
Ácido sórbico & $1,50 \mathrm{~g}$ \\
Nipagin (metil parahidroxibenzoato) & $3,20 \mathrm{~g}$ \\
Formaldeído (40\%) & $1,80 \mathrm{ml}$ \\
Tetraciclina & $56,50 \mathrm{mg}$ \\
Ágar & $30,00 \mathrm{~g}$ \\
Água & $1.400,00 \mathrm{~mL}$ \\
\hline
\end{tabular}

\subsubsection{Método da previsão através das exigências térmicas do inseto}

O método das exigências térmicas baseou-se na contagem de grausdia necessários para o desenvolvimento completo do inseto, ou seja, o somatório de graus-dia acima da temperatura base ( $\mathrm{Tb}$ ) (limiar térmico inferior de desenvolvimento) do inseto até que se complete a constante térmica e esse ins eto se torne adulto.

Semanalmente, foram coletados frutos no talhão, abrindo-os e retirando-se as lagartas para determinação do ínstar predominante na área. 
Essa determinação foi feita com 0 auxílio da tabela ilustrada citada anteriormente (Figura 4). A partir daí, com base na Tb de cada ínstar, determinadas em laboratório (Tabela 2), iniciava-se a contagem de graus-dia. Nessa contagem, a constante térmica foi corrigida através de um fator de correção determinado para cada estação do ano (item 4, Tabela 7). O nível de controle determinado foi quando se dava o desenvolvimento completo do inseto, ou seja, quando o somatório de graus-dia totalizava a constante térmica, através de observações diárias.

Tabela 2. Temperatura base ( $\mathrm{Tb}$ ) para os diferentes ínstares larvais de Ecdytolopha aurantiana (Parra J.R.P inf. pessoal)

\begin{tabular}{crrrr}
\hline \multicolumn{5}{c}{ Instar } \\
\cline { 2 - 4 } & $\mathrm{I}$ & $\mathrm{III}$ & IV \\
\hline 14,2 & 13,6 & 12,1 & 13,3 \\
\hline
\end{tabular}

\subsubsection{Determinação do fator de correção das exigências térmicas para as diferentes estações do ano}

A determinação do fator de correção para cada época do ano foi baseada nas exigências térmicas de $E$. aurantiana criado nas quatro estações do ano de 1999 e comparada com as exigências térmicas determinadas em laboratório. Este estudo foi conduzido na Fazenda "Areão", área experimental da Escola Superior de Agricultura "Luiz de Queiroz" (Esalq)/USP, situada em Piracicaba, SP.

A criação dos insetos foi feita nas diferentes épocas do ano, correspondentes aos meses de janeiro, maio, julho e novembro. Lagartas 
recém eclodidas de E. aurantiana, provenientes do Laboratório de Biologia de Insetos do Departamento de Entomologia, Fitopatologia e Zoologia Agrícola da Esalq/USP, foram "inoculadas" em tubos contendo dieta artificial (Tabela 1) e esses foram colocados em abrigo de madeira, citado anteriormente (Figura 5), sendo levados a um pomar de laranja para imitar as condições de campo, onde permaneceram por todo o período de desenvolvimento do inseto. Foi observada e anotada a data de emergência de adultos, determinando, dessa forma, a constante térmica de cada época somando o número de graus-dia utilizados para o desenvolvimento completo do período (lagarta-adulto). Feito isso, foram comparadas as constantes térmicas das diferentes épocas do ano com a constante térmica determinada em laboratório. $O$ fator de correção para cada estação do ano foi obtido pela divisão da constante térmica obtida no campo pela constante térmica obtida em laboratório.

\subsection{Determinação do nível de controle de $E$. aurantiana utilizando-se armadilha com feromônio sexual (Ferocitrus Furão ${ }^{\circledR}$ )}

A pesquisa foi desenvolvida na Fazenda Entre Rios, da empresa Fischer, no município de Gavião Peixoto, SP, no período de janeiro a dezembro de 2001, em um pomar de laranja da variedade Pêra, com idade de dez anos. O experimento constou de quatro tratamentos, sendo cada um representado por um nível de controle diferente. Os níveis de controle comparados foram 4, 6, 8 e 10 adultos/armadilha/semana, com quatro repetições.

Cada repetição constituiu-se de uma área de dez hectares, monitorada através de uma armadilha adesiva e uma pastilha de feromônio (Ferocitrus Furão ${ }^{\circledR}$ (Figura 6), para atrair os machos da espécie. 
As avaliações foram semanais, seguindo as recomendações de monitoramento proposta por Bento et al. (2001 a, b): (1) instalação da armadilha no terço superior da planta; (2) troca da pastilha a cada 30 dias; (3) identificação do adulto (mariposa) do bicho-furão; (4) avaliação semanal e; (5) utilização de uma armadilha para cada 10 ha (3.000 a 3.500 plantas).

Semanalmente, contava-se e retiravam-se os adultos presentes na armadilha e contava-se o número total de frutos atacados em 20 plantas ao acaso dentro do talhão. O controle da praga, em todos os tratamentos, foi feito pela aplicação do piretróide citado nos itens anteriores, conforme era atingido o nível de controle em questão. A análise estatística foi feita baseando-se no número médio de frutos atacados por planta, nos diferentes níveis de controle testados. Os resultados foram submetidos à análise de variância, sendo, posteriormente, as médias comparadas pelo teste de Tukey, ao nível de $5 \%$ de probabilidade.

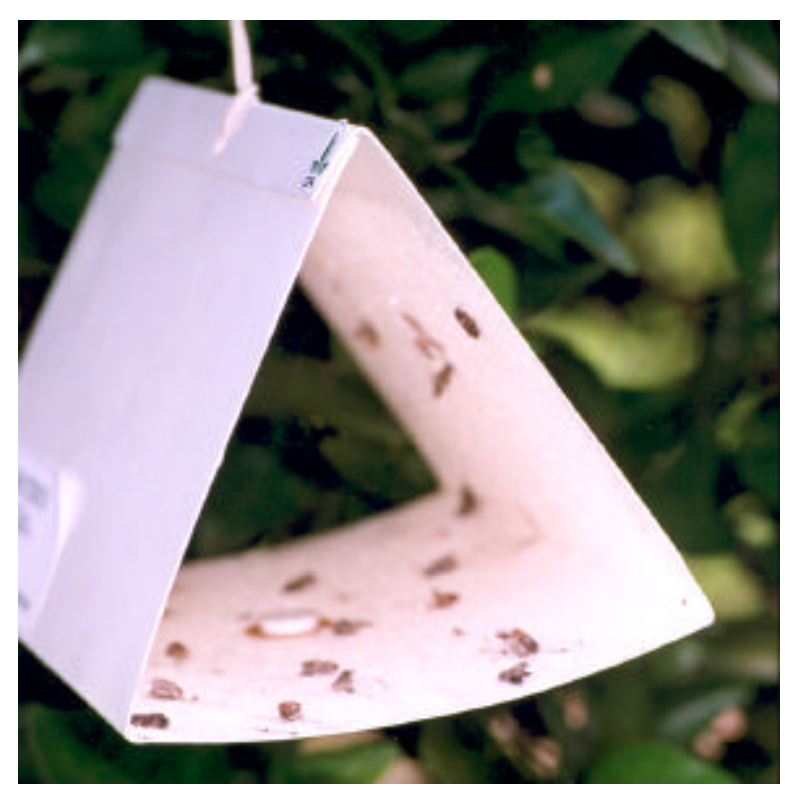

Figura 6 - "Kit" do feromônio sexual Ferocitrus Furão ${ }^{\circledR}$ comercializado no Brasil 
3.3 Determinação do tempo de penetração de lagartas recém eclodidas de E. aurantiana

A pesquisa foi realizada no Laboratório de Biologia de Insetos do Departamento de Entomologia, Fitopatologia e Zoologia Agrícola, da Esalq/USP, no período de 22 a 30 de setembro de 2001, e teve por objetivo avaliar o tempo e profundidade de penetração do bicho-furão, para orientação do produto a ser utilizado no seu controle, após a sua detecção no monitoramento.

Foram utilizados frutos de laranja da variedade Pêra previamente lavados e secos. Nesses frutos foram colocadas, com o auxílio de um pincel fino, lagartas recém eclodidas de E. aurantiana, provenientes da criação em dieta artificial do Laboratório de Biologia de Insetos. O experimento constou de 20 repetições, sendo cada repetição representada por um fruto e uma lagarta recém eclodida. $O$ experimento foi repetido três vezes. Esses frutos eram apoiados em um tubo de vidro para evitar a saída da lagarta (Figura 7). As avaliações foram feitas a cada 20 minutos e era observada a entrada ou não da lagarta no fruto e mortalidade na penetração. Avaliou-se também a profundidade de penetração da lagarta no fruto. 


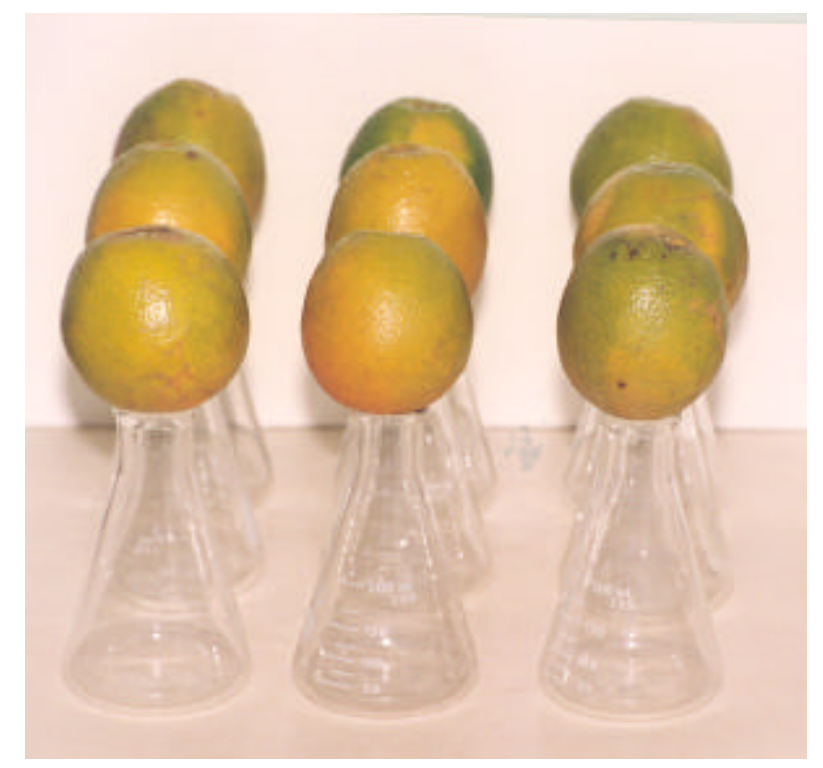

Figura 7-Vista geral do experimento para determinação do tempo de penetração das lagartas recém eclodidas de Ecdytolopha aurantiana em frutos de laranja variedade Pêra

\subsection{Avaliação do efeito de agroquímicos sobre adultos de $E$. aurantiana}

A pesquisa foi realizada na Fazenda Entre Rios, município de Gavião Peixoto, SP, em um pomar de laranja da variedade Pêra, com idade de dez anos, em abril de 2002.

Foram testados sete tratamentos (Tabela 3), cada um deles com sete repetições, sendo cada repetição representada por sete adultos de $E$. aurantiana, mantidos em gaiola de ferro revestida com "voile" (Figura 8). Esses adultos apresentavam dois dias de idade e eram provenientes da criação em dieta artificial do Laboratório de Biologia de Insetos da Esalq/USP. 


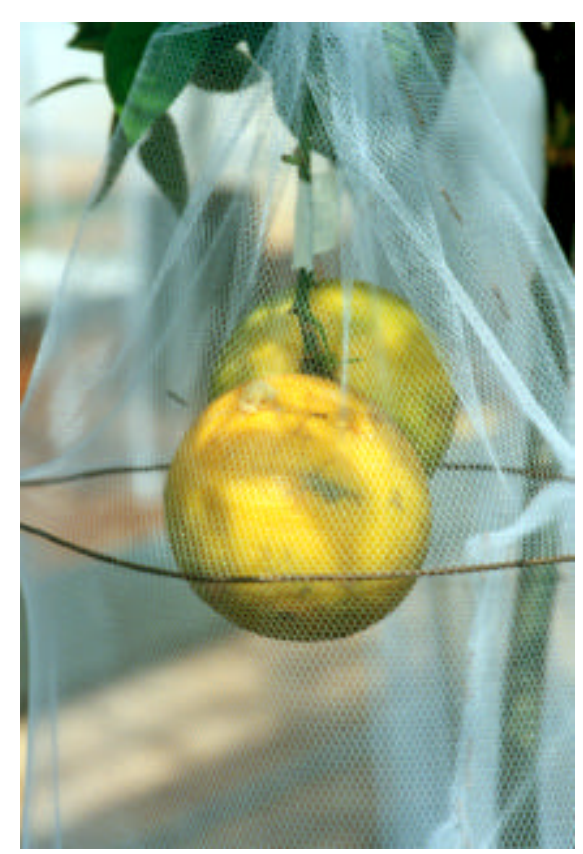

Figura 8 - Gaiolas de ferro contendo frutos de citros e onde foram colocados adultos de Ecdytolopha aurantiana, utilizadas no ensaio de campo para verificar a eficiência de agroquímicos no controle dessa praga

As gaiolas foram distribuídas na linha central de blocos, cada um representado por três linhas de plantas. A distribuição das gaiolas, na linha, foi alternada, colocando-se uma gaiola a cada três plantas. As gaiolas foram colocadas no terço superior e na parte interna da planta, local onde o inseto se abriga (Bento et al., 2001a,b).

A distribuição foi feita minutos antes da aplicação dos agroquímicos, para evitar a ação de predadores, principalmente formigas. Após a aplicação, as gaiolas foram retiradas e colocadas em local adequado para avaliação da mortalidade de adultos. 
Tabela 3. Tratamentos utilizados, e suas respectivas dosagens, visando ao controle de adultos de Ecdytolopha aurantiana

\begin{tabular}{|c|c|c|}
\hline \multicolumn{2}{|c|}{ Tratamentos } & \multirow{2}{*}{$\begin{array}{c}\text { Dosagem } \\
\text { (Litros p.c./2000L } \\
\text { de água) }\end{array}$} \\
\hline Nome comercial & Ingrediente ativo & \\
\hline 1. Talstar 100CE & bifentrine & 0,15 \\
\hline $\begin{array}{l}\text { 2. Talstar + Micromite } \\
+ \text { Natur' Óleo }\end{array}$ & $\begin{array}{c}\text { bifentrine }+ \text { diflubenzuron }+ \\
\text { óleo }\end{array}$ & $0,075+0,50+5,0$ \\
\hline $\begin{array}{l}\text { 3. Talstar + Micromite } \\
+ \text { Natur' Óleo }\end{array}$ & $\begin{array}{c}\text { bifentrine }+ \text { diflubenzuron }+ \\
\text { óleo }\end{array}$ & $0,10+0,35+5,0$ \\
\hline $\begin{array}{l}\text { 4. Talstar + Micromite } \\
\text { + Natur'I Óleo }\end{array}$ & $\begin{array}{l}\text { bifentrine }+ \text { diflubenzuron }+ \\
\text { óleo }\end{array}$ & $0,15+0,35+5,0$ \\
\hline $\begin{array}{l}\text { 5. Micromite } 240 \text { SC + } \\
\text { Natur'l Óleo }\end{array}$ & diflubenzuron + óleo & $0,5+5,0$ \\
\hline $\begin{array}{l}\text { 6. Micromite } 240 \text { SC + } \\
\text { Natur'l Óleo }\end{array}$ & diflubenzuron + óleo & $0,75+5,0$ \\
\hline 7. Testemunha & água & - \\
\hline
\end{tabular}

A aplicação dos agroquímicos foi feita no crepúsculo (horário de atividade do inseto), com turbo atomizador da marca Jacto, acoplado a um trator Massey Ferguson 275, sendo o volume de calda/planta de 20L. A avaliação foi feita $24 \mathrm{~h}$ após a aplicação, registrando-se o número de insetos vivos e mortos e calculando-se, posteriormente, a porcentagem de mortalidade.

Os valores médios de mortalidade, em porcentagem, foram submetidos à análise de variância, sendo as médias comparadas entre si pelo teste de Tukey, ao nível de $5 \%$ de probabilidade. 


\section{RESULTADOS E DISCUSSÃO}

\subsection{Comparação da eficiência de três métodos para monitoramento de adultos de Ecdytolopha aurantiana (Lima, 1927) (Lepidoptera: Tortricidae)}

\subsubsection{Determinação do fator de correção para as diferentes estações do ano para o método de exigências térmicas}

A constante térmica obtida em laboratório por Garcia (1998) para o período larval-pupal do bicho-furão foi de 441,84 GD (Tabela 4), sendo este valor mais próximo do obtido nesse trabalho para o verão (445,48 GD em janeiro). Nas demais estações, os valores da constante térmica obtidos foram superiores ao obtido por Garcia (1998).

A variação destes valores de constante térmica para as diferentes estações do ano mostrou que em determinadas épocas do ano não existe correlação com o valor obtido em laboratório, o que pode influenciar os resultados da aplicação prática das exigências térmicas em campo. Somente o valor da constante térmica obtido no verão (janeiro) (Tabela 4) se aproximou daquele obtido em laboratório (Garcia, 1998).

Como no verão ocorrem as maiores populações do bicho-furão e nestas condições existe uma homogeneidade de ínstares, recomenda-se este tipo de 
amostragem nestas condições, especialmente para propriedades menores, dada àmaior exigência em mão -de-obra por este método.

Sugerem-se pesquisas de validação do método para diferentes condições climáticas e em diferentes épocas do ano, pois dependendo da região do Estado de São Paulo, o bicho-furão deve apresentar número variável de gerações (Garcia, 1998). Os fatores de correção podem ser variáveis de região para região em cada época do ano. Aparentemente, as variações são maiores nos meses mais frios do ano.

Tabela 4. Constante térmica (GD) teórica (de laboratório) e real (de campo) e respectivos fatores de correção para a fase larval-pupal de Ecdytolopha aurantiana obtidos para as diferentes estações do ano. Piracicaba, SP, 1999

\begin{tabular}{ccccc}
\hline Teórica & \multicolumn{4}{c}{ Constante térmica real (k) (campo) } \\
\cline { 2 - 5 } (laboratório) & Janeiro & Maio & Julho & Novembro \\
\hline 467,87 & 445,48 & 543,28 & 503,37 & 519,74 \\
& & Fator de correção $(F)$ & \\
- & 0,952 & 1,160 & 1,075 & 1,110 \\
\hline
\end{tabular}

\subsubsection{Comparação das datas indicadas e número de frutos atacados para cada método de amostragem}

O método de amostragem com armadilha de feromônio sexual e o método da dieta artificial indicaram o momento de controle de E. aurantiana na mesma época, em média, considerando-se os níveis de controle de $60 \%$ dos adultos emergidos no método da dieta artificial e quatro adultos/armadilha/semana no método da armadilha com feromônio (Tabela 5). 
O método da previsão através das exigências térmicas do inseto indicou 0 momento de controle cerca de dois a cinco dias depois dos outros métodos estudados (Tabela 6).

Entretanto, apesar da diferença entre o método de amostragem por exigências térmicas e os demais métodos, não houve diferenças estatísticas entre os três quanto ao número de frutos atacados (Tabela 6). Esta diferença observada entre métodos, sem diferença na porcentagem de frutos atacados, dá uma segurança ao agricultor nos dois primeiros métodos, indicando que o controle não precisa ser feito imediatamente, caso muito freqüente em agricultura, onde devido a outras atividades, o controle não pode ser feito tão logo seja registrado o nível de controle.

Tabela 5. Definição das datas de aplicação de agroquímicos para controle de Ecdytolopha aurantiana, com base em três métodos de amostragem. Gavião Peixoto, SP, 2001

\begin{tabular}{|c|c|c|c|c|c|c|c|c|c|c|}
\hline \multirow{2}{*}{ Método } & \multicolumn{3}{|c|}{ Fev } & \multirow{2}{*}{ Mar } & \multicolumn{2}{|c|}{ Abr } & \multicolumn{3}{|c|}{ Out } & \multirow{2}{*}{ Total } \\
\hline & $1^{a}$ & $2^{a}$ & $3^{a}$ & & $1^{a}$ & $2^{a}$ & $1^{a}$ & $2^{a}$ & $3^{a}$ & \\
\hline $\begin{array}{l}\text { Armadilhas de } \\
\text { feromônio }\end{array}$ & 07 & 14 & 21 & 14 & 11 & 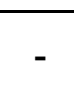 & 03 & - & - & 06 \\
\hline Dieta artificial & 09 & 12 & 18 & 19 & 14 & 22 & 05 & 10 & 18 & 09 \\
\hline Exigências térmicas & 12 & 17 & 23 & 20 & 16 & 26 & 08 & 14 & 23 & 09 \\
\hline
\end{tabular}


Tabela 6. Número médio de frutos atacados/planta nos diferentes métodos de amostragem para Ecdytolopha aurantiana. Gavião Peixoto, SP, 2001

\begin{tabular}{|c|c|c|c|c|c|c|c|}
\hline Método & Fev & Mar & Abr & Mai & Out & Nov & Total \\
\hline $\begin{array}{l}\text { Armadilhas de } \\
\text { feromônio }\end{array}$ & 5 & 3 & 2 & 1 & 4 & 2 & 17 a $(1,47)$ \\
\hline Dieta artificial & 7 & 3 & 1 & 1 & 3 & 1 & 16 a $(2,34)$ \\
\hline Exigências térmicas & 3 & 1 & 1 & 1 & 4 & 2 & $12 \mathrm{a}(1,26)$ \\
\hline
\end{tabular}

\subsection{Determinação do nível de controle de $E$. aurantina utilizando-se armadilha com feromônio sexual}

Os resultados obtidos nos tratamentos com níveis de controle de 4 e 6 adultos/armadilha/semana não diferiram estatisticamente entre si, pois mantiveram o número médio de frutos atacados por $E$. aurantiana entre $0,5 \mathrm{e}$ 1,0 por planta, com número de aplicações de inseticidas muito próximos (Tabela 7). Estes resultados coincidem com aqueles obtidos por Bento et al. (2001a) que trabalhando em diferentes áreas citrícolas de São Paulo e Minas Gerais, encontraram o número de 6 machos/armadilha como o ideal para se iniciar o controle da praga, pois com este nível ocorreram perdas de apenas 0,6 frutos/planta. Para os tratamentos com 8 e 10 adultos por armadilha, a média de frutos atacados foi de 4 por planta e o número de aplicações para o controle da praga aumentou em relação aos tratamentos mencionados anteriormente (Tabela 7). Portanto, além da redução de frutos atacados/planta, houve com $4 \mathrm{e}$ 6 adultos/armadilha, redução do número de aplicações de inseticidas. 
Tabela 7. Número médio de frutos de laranja Pêra atacados por Ecdytolopha aurantiana por planta, em cada nível de controle testado (com armadilha de feromônio sexual), e o número médio de aplicações de inseticidas em cada tratamento. Gavião Peixoto, SP, 2001

\begin{tabular}{ccc}
\hline Nível de controle & $\begin{array}{c}\text { Número médio de } \\
\text { frutos atacados }\end{array}$ & $\begin{array}{c}\text { Número médio de } \\
\text { aplicações de inseticidas }\end{array}$ \\
\hline 4 adultos/armadilha & $0,5 \pm 0,11 \mathrm{a}$ & $3,5(2-5)$ \\
6 adultos/armadilha & $1,0 \pm 0,17 \mathrm{a}$ & $3,0(2-4)$ \\
8 adultos/armadilha & $4,0 \pm 0,49 \mathrm{~b}$ & $4,5(3-6)$ \\
10 adultos/armadilha & $4,0 \pm 0,64 \mathrm{~b}$ & $4,8(3-7)$ \\
\hline $\begin{array}{l}\text { Os valores entre parênteses referem-se ao intervalo de variação para o número de aplicações } \\
\text { de inseticidas }\end{array}$
\end{tabular}

\subsection{Determinação do tempo e profundidade de penetração de lagartas recém eclodidas de $E$. aurantiana em frutos}

O tempo médio de penetração da lagarta em frutos de laranja variedade 'Pêra' foi de 3 horas e 43 minutos, com tempo mínimo de 2 horas e 8 minutos e máximo de 6 horas e 52 minutos, em média (Tabela 8).

Após 24 horas da "inoculação" da lagarta recém eclodida no fruto, essa penetrou, em média, 3,9 mm no fruto, não atingindo a polpa (Tabela 9). Entretanto, após 48 horas, 50\% das lagartas atingiram a polpa, chegando, em média, a 4,6 mm de profundidade no fruto (Tabela 9). Após 72 horas, 50\% das lagartas se localizavam na casca, cerca de $7 \%$ estavam na interface casca/polpa e o restante na polpa (Tabela 9). 
Tabela 8. Tempo de penetração de lagartas recém eclodidas de Ecdytolopha aurantiana em frutos de laranja var. 'Pêra'

\begin{tabular}{ccccc}
\hline \multirow{2}{*}{$\begin{array}{c}\text { Total de lagartas } \\
\text { inoculadas }\end{array}$} & $\begin{array}{c}\text { No. lagartas } \\
\text { avaliadas }\end{array}$ & \multicolumn{2}{c}{ Tempo (horas:minutos) } \\
\cline { 3 - 5 } & 10 & $2: 15$ & $3: 34$ & $6: 15$ \\
\hline 20 & 12 & $2: 15$ & $3: 22$ & $6: 00$ \\
20 & 12 & $1: 55$ & $4: 12$ & $8: 20$ \\
20 & 11,34 & $2: 08$ & $3: 43$ & $6: 52$ \\
Média & & & \\
\hline
\end{tabular}

Tabela 9. Profundidade de penetração e mortalidade (72 horas após a inoculação) de lagartas recém eclodidas de Ecdytolopha aurantiana em diferentes intervalos após a inoculação em frutos de laranja variedade 'Pêra'

\begin{tabular}{|c|c|c|c|}
\hline \multirow{2}{*}{$\begin{array}{l}\text { Profundidade média } \\
\text { de penetração }(\mathrm{mm})\end{array}$} & \multicolumn{3}{|c|}{ Localização da lagarta no fruto (\%) } \\
\hline & Casca & Casca/polpa & Polpa \\
\hline \multicolumn{4}{|c|}{24 horas após a inoculação } \\
\hline 3,88 & 100 & - & - \\
\hline \multicolumn{4}{|c|}{48 horas após a inoculação } \\
\hline 4,55 & 50 & - & 50 \\
\hline \multicolumn{4}{|c|}{72 horas após a inoculação } \\
\hline 4,06 & 50 & 7,1 & 42,9 \\
\hline Mortalidade (\%) & & 32 & \\
\hline
\end{tabular}

Provavelmente, após 72 horas da "inoculação" algumas lagartas estavam na interface casca/polpa para a eliminação dos excrementos produzidos, pelo orifício de entrada, comportamento este que diferencia os danos causados pelo 
bicho-furão daqueles causados pelas moscas-das-frutas, caracterizando seu ataque.

A mortalidade natural foi alta, dificultando a avaliação da eficiência de produtos químicos para lagartas pequenas do bicho-furão (Tabela 9). Provavelmente as diferenças de resultados de trabalhos com controle químico do bicho-furão, se devem a esta alta mortalidade natural no campo.

Esses resultados mostraram um curto período de penetração das lagartas nos frutos, indicando que, quaisquer que sejam os produtos utilizados para o controle de lagartas recém eclodidas, as medidas de controle devem ser aplicadas antes da eclosão das lagartas. Para tanto, deve-se considerar o período de pré-oviposição das fêmeas, além do período de incubação, que são, em média, de 2 e 5 (4 a 7 dias) dias, respectivamente, segundo Garcia (1998). Portanto, os resultados indicaram que a adoção de medida de controle de lagartas deve ser 6 a 8 dias após a emergência dos adultos (métodos de exigências térmicas e de dietas artificiais) ou de coleta de adultos na armadilha (método de feromônio sexual). No caso de se utilizar uma opção biológica de controle (Bacillus thuringiensis), ele deve ser feito 6 a 8 dias após a emergência e/ou coleta, pois este produto não tem "ação de choque" e seu efeito seria sobre lagartas recém eclodidas que se alimentariam da bactéria. No caso de produtos químicos com "ação de choque" (como piretróides), a aplicação deve ser feita tão logo haja a emergência ou a coleta dos adultos nas armadilhas.

\subsection{Avaliação do efeito de agroquímicos sobre adultos de E. aurantiana}

A mortalidade foi maior nos tratamentos com bifentrine (piretróide) e, embora numericamente tal mortalidade tenha sido maior na maior dosagem, estatisticamente não diferiu cas dosagens menores (Tabela 10). Mesmo com 
óleo, os tratamentos contendo diflubenzuron não diferiram da testemunha (Tabela 10). A mortalidade elevada observada na testemunha (30\%) (Tabela 10) foi devida àação de formigas, entretanto, sem comprometer os re sultados.

Tabela 10. Mortalidade (\%) de adultos de Ecdytolopha aurantiana em campo, nos diferentes tratamentos utilizados. Gavião Peixoto, SP, 2001

\begin{tabular}{lcc}
\hline \multicolumn{1}{c}{$\begin{array}{c}\text { Tratamentos } \\
\text { (ingrediente ativo) }\end{array}$} & $\begin{array}{c}\text { Dosagem } \\
\text { (litros p.c./2.000L } \\
\text { de água) }\end{array}$ & $\begin{array}{c}\text { Mortalidade } \\
\text { (\%) }\end{array}$ \\
\hline Bifentrine + diflubenzuron + óleo & $0,075+0,50+5,0$ & $81 \mathrm{a}$ \\
Bifentrine + diflubenzuron + óleo & $0,15+0,35+5,0$ & $51 \mathrm{ab}$ \\
Bifentrine + diflubenzuron + óleo & $0,10+0,35+5,0$ & $46 \mathrm{ab}$ \\
Testemunha (água) & - & $30 \mathrm{bc}$ \\
Bifentrine & 0,15 & $25 \mathrm{bc}$ \\
Diflubenzuron + óleo & $0,5+5,0$ & $11 \mathrm{bc}$ \\
Diflubenzuron + óleo & $0,75+5,0$ & $5 \mathrm{c}$ \\
\hline
\end{tabular}

Médias seguidas da mesma letra, na vertical, não diferem estatisticamente entre si pelo teste de Tukey, ao nível de $5 \%$ de probabilidade. Dados transformados para arc seno $\sqrt{x / 100}$.

Aparentemente, houve um feito sinérgico do bifentrine mais óleo, pois isoladamente o bifentrine não diferiu da testemunha e o diflubenzuron mais óleo também não controlou os adultos de $E$. aurantiana. A hipótese de que 0 regulador de crescimento, diflubenzuron, teria uma ação ovicida, aparentemente não foi comprovada, pois a sua eficiência foi baixa, mesmo associado com óleo. 


\section{CONCLUSÕES}

1. Os três métodos de monitoramento de Ecdytolopha aurantiana (Lima, 1927) podem ser utilizados em condições de campo;

2. O método de monitoramento do bicho-furão por meio de feromônio sexual é o que exige menor mão-de-obra;

3. O método de monitoramento através de exigências térmicas é aplicável no verão, demandando fatores de correção para as demais estações do ano;

4. O nível de controle por monitoramento com feromônio sexual é de 4 a 6 adultos/semana; a partir destes números, as perdas são maiores a despeito do maior número de aplicações de produtos químicos;

5. Como o tempo de penetração da lagarta do bicho-furão é rápido (100\% em 24 h), com cerca de 42,9\% atingindo a polpa em 72 h, torna-se difícil o controle do inseto nesta fase através de produtos químicos ou biológicos;

6. A alta mortalidade larval durante a penetração no fruto pode mascarar os resultados de avaliação da eficiência de controle com produtos químicos ou biológicos;

7. $O$ piretróide bifentrine é eficiente no controle de adultos de $E$. aurantiana, desde que adicionado a óleo mineral. 


\subsection{Considerações finais}

Os três métodos de amostragem para monitoramento do bicho-furão, Ecdytolopha aurantiana (Lima, 1927) podem ser utilizados pelo agricultor, embora no caso do método utilizando-se exigências térmicas, exista variações, dependendo da época do ano, o que poderá exigir a adoção de fatores de correção dependendo da região e da estação do ano. As maiores variações ocorrem nas épocas mais frias do ano. Em termos de custo/benefício, sem dúvida, o método de monitoramento com feromônio sexual é mais barato, pois demanda apenas a contagem semanal, enquanto os demais métodos exigem, pelo menos, próximo à emergência, avaliações diárias. Os métodos são aparentemente seguros, pois mesmo naquele de exigências térmicas, que exigiu 2,5 dias a mais em relação aos demais métodos para início do controle, ainda assim a porcentagem de frutos atacados foi semelhante àquela encontrada nos outros métodos.

O número de adultos por armadilha de feromônio sexual está entre 4 e 6 , pois não houve diferença estatística entre os tratamentos com 4 ou 6 adultos por armadilha (Tabela 7), considerando-se o número de frutos atacados pelo bicho-furão

O tempo de penetração das lagartas nos frutos é muito rápido, o que torna difícil o controle da praga com produtos biológicos, pois com $24 \mathrm{~h}$ se dá a penetração de $100 \%$ das lagartas e com 72 h, 42,9\% já está na polpa.

O piretróide bifentrine, associado ao diflubenzuron e óleo, foi o mais eficiente no controle de adultos de E. aurantiana, havendo, aparentemente, um efeito sinérgico do óleo e bifentrine. 


\section{REFERÊNCIAS BIBLIOGRÁFICAS}

BENTO, J. M.S.; VILELA, E.V.; PARRA, J.R.P.; LEAL, W.S. Monitoramento do bicho-furão-dos-citros com feromônio sexual: bases comportamentais para utilização dessa nova estratégia. Laranja, v.22, p.351-366, 2001b.

BENTO, J. M.S.; MOLINA, R.M.S.; PARRA, J.R.P.; PARRA, A.L.G.C.; CARVALHO, D.R. Protandria no bicho-furão dos citros, Ecdytolopha aurantiana (Lepidoptera, Tortricidae). In: CONGRESSO BRASILEIRO DE ENTOMOLOGIA, 19. Manaus,2002. Resumos. Piracicaba: SEB, 2002. v1, p. 35-36

BENTO, J.M.S.; PARRA, J.R.P.; VILELA, E.F.; WALDER, J.M.; LEAL, W.S. Sexual behavior and diel activity of citrus fruit borer Ecdytolopha aurantiana (Lepidoptera: Tortricidae). Journal of Chemical Ecology, v.27, n.10, p.2053-65, 2001a.

CITRICULTURA sofre o maior ataque do bicho furão dos últimos anos. Jornal do Fundecitrus, v. 12, n. 75, p. 4-5, mar./abr. 1996.

FNP CCONSULTORIA \& COMÉRCIO. Agrianual - 2001: anuário da agricultura brasileira. São Paulo, 2001. 516p.

FONSECA, J.P. da. Combate à lagarta das laranjas, Gymnandrosoma aurantianum Costa Lima. Chácaras e Quintais, v.50, p.215-216, 1934.

FUNDECITRUS. Tecnologia contra o bicho-furão. Revista do Fundecitrus, n. 96, p.8-10. 2000. 
FUNDECITRUS. Manual de manejo "bicho-furão". São Paulo, 2003.7p.

GALLO, D.; NAKANO, O.; SILVEIRA NETO, S.; CARVALHO, R.P.L.; BAPTISTA, G.C. de; BERTI FILHO, E.; PARRA, J.R.P.; ZUCCHI, R.A.; ALVES, S.B.; VENDRAMIM, J.D.; MARCHINI, L.C.; LOPES, J.R.S.; OMOTO, C. Entomologia agrícola. Piracicaba: Fealq, 2002. 920p.

GARCIA, M.S. Bioecologia e potencial de controle biológico de Ecdytolopha. aurantiana (Lima 1927) (Lepidoptera : Tortricidae), o bicho-furão-dos-citros, através de Trichogramma pretiosum Riley, 1879. Piracicaba, 1998. 118p. Tese (Doutorado) - Escola Superior de Agricultura "Luis de Queiroz", Universidade de São Paulo.

GARCIA, M.S.; PARRA, J.R.P. Comparação de dietas artificiais, com fontes protéicas variáveis, para criação de E. aurantiana (Lima 1927) (Lepidoptera: Tortricidae). Anais da Sociedade Entomológica do Brasil, v.28, n.2, p.219-232, 1999.

GARCIA, M.S.; PARRA, J.R.P.; IAROSSI, A.R.; KASTEN Jr., P. Bioecologia do bicho-furão e perspectiva de controle. Laranja, v. 19, n.2, p. 249-260, 1998.

GUERREIRO, J. C.; FABIANO, L. A. ; PAZINI, W. C.; BUSOLI, A. C. Eficiência de inseticidas químicos e biológicos no controle de bicho-furão-dos-citros Ecdytolopha aurantiana (Lepdoptera : Tortricidae). In: CONGRESSO BRASILEIRO DE ENTOMOLOGIA, 16., Salvador, 1997. Resumos. Salvador: SEB, 1997. p. 181.

LEAL, W.S.; BENTO, J.M.S.; MURATA, Y.; ONO, M.; PARRA, J.R.P.; VILELA, E.F. Identification, synthesis, and field evaluation of the sex pheromone of the citrus fruit borer Ecdytolopha aurantiana. Journal of Chemical Ecology, v.27, n.10, p.2041-2051, 2001.

LIMA, A. C. Sobre um novo microlepidóptero, cuja lagarta é praga das laranjeiras no Distrito Federal. Chácaras e Quintais, v.36, p.33-35, 1927. 
LIMA, A. C. Insetos do Brasil: Lepdópteros. Rio de Janeiro: Escola Nacional de Agronomia, 1945. v. 1.

MASSAMBANI, A. H.; PINTO, R. A.; SILVA, J. L.; GRAVENA, S. Inseticidas biológicos e fisiológicos no controle do bicho-furão Ecdytolopha aurantiana em citros. In: CONGRESSO BRASILEIRO DE ENTOMOLOGIA, 16. Salvador 1997. Resumos. Salvador: SEB, 1997. p.105.

MOLINA, R.M. S. Bioecologia de duas espécies de Trichogramma para o controle de Ecdytolopha aurantiana (Lima, 1927) (Lepidoptera : Tortricidae) em citros. Piracicaba, 2003. 80p. Dissertação (Mestrado) - Escola Superior de Agricultura “Luiz de Queiroz”, Universidade de São Paulo.

NAKANO, O.; LEITE, A.C. Avaliação do ataque do bicho-furão em função de parâmetros climáticos. Laranja, v.19, n.1, p.39-47, 1998.

NAKANO, O.; SOARES, M.G. Bicho-furão: biologia, hábitos e controle. Laranja, v.16, n.1, p.209-221, 1995.

PARRA, J. R.P. Controle biológico das pragas dos citros. Boletim Citrícola, n.21, p.37, 2002.

PARRA, J. R. P.; KASTEN Jr., P.; MOLINA, R.M.S.; HADDAD, M.L. Efeito do $\mathrm{pH}$ no desenvolvimento do bicho-furão. Laranja, v.22, n.2, p.299-320, 2001

PAZINI,W.C.; BUSOLI, A. C. Eficiência de inseticidas no controle do bichofurão-dos-citros Ecdytolopha aurantiana (Lepidoptera : Tortricidae). In: CONGRESSO BRASILEIRO DE ENTOMOLOGIA,16., Salvador,1997. Resumos. Salvador: SEB, 1997. p.181.

PINTO, W.B. S. "Bicho-furão" considerado hoje uma das principais pragas da nossa citricultura. Laranja \& Cia, n.38, p.4-5, 1994.

PINTO, W.B. S. Mariposa-da-laranja ou bicho-furão: uma praga que está aumentando na citricultura. Laranja, v.16, n.1, p.243-250, 1995. 
PINTO, W.B. S. "Bicho-furão" :catação reduz infestação. Laranja \& CIA, n. 44, p. 13, 1996.

PINTO, W. B. S.; PRATES, H. S.; NOGUEIRA, N. L. Efeito de inseticidasacaricidas no controle de lagartas ( bicho furão ) mariposa das laranjas Ecdytolopha aurantiana (Lima, 1927) (Lepidoptera, Tortricidae) In: CONGRESSO BRASILEIRO DE ENTOMOLOGIA, 16., Salvador, 1997. Resumos. Salvador: SEB,1997. p. 183.

POWELL, J.A.; RASOWSKI, J.; BROWWN, R.L. Olethreutinae. In: HEPPNER, J.B. (Ed.) Atlas of Neotropical Lepidoptera. Gainesville: Association for Tropical Lepidoptera, 1995.

PRATES, H.S. Resultados recentes do controle do bicho-furão - lagarta da mariposa das laranjas - Gymnandrosoma aurantianum (Lima, 1927) em citros. Informativo Coopercitrus, n.71, p.20-21, 1992.

PRATES, H.S.; PINTO, W.B.S. Ocorrência da mariposa das laranjas (Gymnandrosoma aurantianum Lima, 1927) na citricultura paulista. Laranja, v.9, n.1, p.117-124, 1988.

PRATES, H.S.; PINTO, W.B.S. Controle do "bicho-furão" na citricultura. Informativo Coopercitrus, n.60, p.18-24, 1991.

PRATES, H.S.; PINTO, W.B.S. Controle associado do "Bicho-furão" em pomares cítricos. Laranja, v.13, n 2. p. 625-634, 1992.

PRATES, H.S.; PINTO, W.B.S. Ocorrência do "bicho-furão" nas principais áreas citrícolas paulistas. Laranja, n.16, p.237-242, 1995.

PRATES, H.S.; PINTO, W.B.S.; CAETANO, A.A. Controle da "mariposa das laranjas" - Gymnandrosoma aurantianum Lima, 1927 (Lepidoptera, Olethreutidae). In: CONGRESSO BRASILEIRO DE FRUTICULTURA, 6., Recife, 1981. Anais. Recife: SBF, 1981. v.2, p.552-557. 
SCHULTZ, E.T. La mariposa de los naranjos (Gymnandrosoma sp. ). Revista Industrial Agrícola de Tucuman, v.29, p. 87-90, 1939.

WHITE, G.L. Outbreak of Ecdytolopha aurantiana (Lima) on Citrus in Trinidad. FAO Plant Protection Bulletin, v.14, n.2, p.130-132, 1993.

ZUCCHI, R.A.; SILVEIRA NETO, S.; NAKANO, O. Guia de identificação de pragas agrícolas. Piracicaba: FEALQ, 1993. 139p. 